OPEN ACCESS

Edited by:

Marcia G. Ory,

School of Public Health, Texas A\&M University, United States

Reviewed by:

Krista Mincey,

Xavier University of Louisiana, United States

Matthew Lee Smith,

Texas A\&M University, United States

*Correspondence:

Vasoontara Sbirakos Yiengprugsawan vasoontara.yieng@anu.edu.au;

v.yiengpr@unsw.edu.au

Specialty section: This article was submitted to Public Health Education and Promotion,

a section of the journa Frontiers in Public Health

Received: 09 November 2018 Accepted: 02 October 2019 Published: 23 October 2019

Citation: Yiengprugsawan VS and Browning CJ (2019) Non-communicable Diseases and Cognitive Impairment: Pathways and Shared Behavioral Risk Factors Among Older Chinese. Front. Public Health 7:296 doi: 10.3389/fpubh.2019.00296

\section{Non-communicable Diseases and Cognitive Impairment: Pathways and Shared Behavioral Risk Factors Among Older Chinese}

\author{
Vasoontara Sbirakos Yiengprugsawan ${ }^{1,2 *}$ and Colette Joy Browning ${ }^{1,3,4}$ \\ ${ }^{1}$ Centre for Research on Ageing, Health and Wellbeing (CRAHW), Research School of Population Health, The Australian \\ National University, Canberra, ACT, Australia, ${ }^{2}$ Australian Research Council Centre of Excellence in Population Ageing \\ Research (CEPAR), University of New South Wales, Kensington, NSW, Australia, ${ }^{3}$ School of Nursing and Healthcare \\ Professions, Federation University, Ballarat, VIC, Australia, ${ }^{4}$ International Primary Health Care Research Institute, \\ Shenzhen, China
}

Population aging has brought about a number of challenges to public health and primary health care systems due to increases in the prevalence of non-communicable diseases (NCDs). As a country with one of the largest populations globally, China is confronting a rising number of chronic NCDs including cardiometabolic related conditions. This minireview investigates the link between NCDs and cognitive impairment through common risk factors. Identifying risk factors is important for the prevention and management of these chronic conditions. In addition, this review also identifies the role of primary health care services in reducing behavioral risk factors for NCDs and cognitive impairment. Addressing shared determinants and pathways is important in the design of public health interventions and primary health care services in China. Monitoring and management of NCD biomarkers and behavioral risk factors may also be beneficial for cognitive health among older Chinese.

Keywords: aging, China, cognitive decline, chronic conditions, lifestyle risk factors

\section{INTRODUCTION}

As China's population ages, the country is confronted with rapidly changing health profiles. According to the Global Burden of Diseases, the pattern of causes of deaths has also changed significantly away from communicable diseases and as of 2016, the main causes of death were cardiovascular diseases $(41 \%)$, cancers $(25 \%)$, chronic respiratory diseases $(10 \%)$, and diabetes (4\%) (1). In addition to these "Big 4" non-communicable diseases (NCDs), neurological disorders including Alzheimer's disease and other dementias further contributed to 5\% of pre-mature mortality. This figure is expected to increase as China's population ages $(1,2)$.

NCDs are inextricably linked to natural aging processes and various modifiable risk factors, and as a result, chronic conditions generally have common determinants and many shared risk factors, most of which are amenable to prevention and amelioration over the lifecourse $(3,4)$. NCDs have direct or indirect impacts on activities of daily living resulting from these conditions (5). Furthermore, there has been emerging literature on the potential links between chronic non-communicable diseases and cognitive impairment, notably highlighting common mid-life modifiable risk factors (e.g., mid-life hypertension, diabetes, smoking), improving integrated chronic care management, and reducing impacts on overall quality of life (6-8). 
The United Nations Sustainable Development Goals initiative has called for a reduction by one third of premature mortality from NCDs (9). If this is to be achieved in China, risk factor reduction needs to be a focus. An analysis of Chinese Burden of Disease risk factor data (blood pressure, body mass index, high cholesterol, high fasting glucose, smoking, and inactivity) in people aged 30-70 years, found that if risk reduction targets were met by 2030, one million deaths could be avoided (10).

While there is good evidence that the prevalence of cognitive impairment among older Chinese is greater than would be expected from age-related health decline $(2,11,12)$, information is still limited on the relationships between NCD co-morbidities, common risk factors, and cognitive impairment. This review looks at common pathways for NCDs, Cognitive Impairment (CI), and Mild Cognitive Impairment (MCI) whereby $\mathrm{CI}$ is a broad term that can range from mild to severe (13). The purpose of this review is to specifically focus on older Chinese to investigate associations between NCDs, CI as well as MCI, and common risk factors, as well as to identify the role of primary health care services in reducing common behavioral risk factors. Notably, the majority of these studies reported focus on MCI with some examples of CI included. The role of key socio-demographic factors and primary health care in these associations will be also presented in the mini-review.

The review will contribute to a better understanding of the pathways and interrelationships between NCDs, CI/MCI and their risk factors among older Chinese. It will also discuss effective health promotion and prevention strategies targeting modifiable risk factors that may prevent or delay the onset and progress of late-life cognitive impairment.

\section{METHODS}

This mini review will cover the range of observational population-based studies conducted between 2010 and 2018 focusing primarily on CI/MCI among non-clinical samples of adults aged 50 years and over in mainland China. Studies that restricted the sample ages to $75+$ years and the oldest old were not included in the review. Main searches were conducted in English through international databases such as MEDLINE, PubMed, Scopus, and Web of Science. Key search terms, for example, include "cognitive impairment" "Mild Cognitive Impairment" "MCI" "Alzheimer's" "dementia" "cardiovascular diseases" "hypertension" "diabetes" "blood pressure" "chronic diseases" (Table 1).

\section{Definition and Prevalence of $\mathrm{Cl} / \mathrm{MCl}$ Among Older People in China}

We focus on CI and MCI as there is evidence that these conditions could lead to an increased risk of developing more severe neurological conditions such as dementia and Alzheimer's disease $(2,11,12)$. Commonly used international diagnostic criteria for CI and MCI rely on cognitive function assessments such as the Montreal Cognitive Assessment (MoCA) and the Mini-Mental State Examination (MMSE), both with scores ranging from 0 to 30 points. MCI diagnosis is often based on Petersen's criteria which include memory problems in the absence of dementia (27-29). In the Chinese literature, using MMSE, CI has a cut-off score of 24, while MCI generally has the cut-off score of 26 (30-32). Taking into account the educational differential effect on cognitive performance, MCI among older Chinese was commonly defined by an MMSE score of $<17$ in the illiterate group, $<22$ in the primary school group, and $<26$ in the junior school and above (19). Corresponding cut-off scores for CI were reported at 17,20, and 24, respectively (23).

According to a meta-analysis of 22 studies among older people aged 60 years and over in China, $12.7 \%$ have experienced MCI and the prevalence was lower in more economically advanced Eastern areas (9.6\%) compared to Western China (14.7\%) (11). A more recent systematic review among 48 studies across 22 provinces in China reported the pooled prevalence of MCI in the older Chinese aged 60 years and over was $14.7 \%$; the prevalence was $16.7 \%$ in clinical samples and $14.6 \%$ in nonclinical samples (12).

\section{RESULTS}

\section{Relationships Between Cardio-Metabolic Risk Factors and $\mathrm{Cl} / \mathrm{MCl}$ Diabetes and Obesity}

There is increasing evidence on the significant relationship between type 2 diabetes mellitus and CI/MCI among older adults in China (14, 15, 33). A cross-sectional study (aged 65+in Northern China) revealed risk factors for MCI to be age at onset and biomarkers of type 2 diabetes severity such as fasting plasma glucose, glycosylated hemoglobin, and immunoreactive insulin (14). An urban population-based study (aged 55+ in Shanghai) further confirmed that T2DM was not only a risk factor for MCI but also associated with the progression to Alzheimer's disease after adjusting for other possible covariates (15). However, another study (aged 60+ in Tianjin) revealed that even in the absence of type 2 diabetes, being overweight and/or obese are risk factors for MCI (16). Similarly a community-based study (aged 55+ in rural Xian) found that the presence of both type 2 diabetes and abdominal obesity was associated with an increased risk of cognitive impairment by more than double (17).

\section{Cardiovascular Diseases, Blood Pressure, and Cholesterol}

Cardiovascular diseases and cognitive decline share common risk factors including high blood pressure, which was found to be a predictor for CI/MCI among older adults $(32,34)$. A cross-sectional study (aged $60+$ in Beijing) reported a higher prevalence of MCI among hypertensive individuals and also the prevalence of MCI was lower in those treated than in those not treated (18). Another cross-sectional study (aged 60+ in Tianjin) also reported similar findings with high blood pressure associated with a higher risk of cognitive impairment compared to normal blood pressure participants (95\% CI: 1.07-2.54) (19). In addition to hypertension, coronary heart disease, total cholesterol, and low-density lipoprotein cholesterol were found to be independent risk factors for MCI and elevated high-density 
TABLE 1 | Description of studies illustrating relationships between cognitive impairment and non-communicable diseases.

\begin{tabular}{|c|c|c|c|c|c|}
\hline Studies & $\mathrm{N}$ and age (years) & Areas & Study design & Cognitive impairment (Cl/MCl) & Cardiometabolic and lifestyle factors \\
\hline Gao et al. (14) & $\begin{array}{l}N=8213 \\
\text { Aged } 65+\end{array}$ & Tianjin, Northern China & $\begin{array}{l}\text { Cross-sectional } \\
\text { (2010) }\end{array}$ & $\begin{array}{l}\text { Mini Mental State Examination } \\
\text { MMSE } \leq 27 \\
\text { Montreal Cognitive Assessment } \\
\text { MoCA }<26\end{array}$ & $\begin{array}{l}\text { Fasting plasma glucose (FPG), glycosylated hemoglobin } \\
\text { (HbA1c) and immunoreactive insulin (IRI) were associated } \\
\text { with increasing risk for } \mathrm{MCl} \text { with Type } 2 \text { diabetes (T2DM). }\end{array}$ \\
\hline Li et al. (15) & $\begin{array}{l}N=525 \\
\text { Aged } 55+\end{array}$ & Shanghai & $\begin{array}{l}\text { Cross-sectional } \\
\text { (2011) }\end{array}$ & $\begin{array}{l}\text { MMSE } \leq 27 \\
M o C A<26\end{array}$ & $\begin{array}{l}\text { T2DM was a risk factor for MCl progressive to Alzheimer's } \\
\text { disease. }\end{array}$ \\
\hline Wang et al. (16) & $\begin{array}{l}N=480 \\
\text { Aged } 65+\end{array}$ & Tianjin, Northern China & $\begin{array}{l}\text { Longitudinal } \\
(2008-2014)\end{array}$ & $\begin{array}{l}\text { MMSE }<20 \text { (primary education); } \\
M M S E<24 \text { ( }>\text { primary education) } \\
\text { MoCA }<25 \text { ( } \leq 12 \text { years of education); } \\
\text { MoCA }<26 \text { ( }>12 \text { years of education) }\end{array}$ & $\begin{array}{l}\text { Being overweight or obese at baseline was associated with } \\
\text { an increased risk of both amnestic and non-amnestic } \mathrm{MCl} \text {. } \\
\text { An increased body mass index at } 6 \text {-year follow-up also } \\
\text { increased the risk of non-amnestic } \mathrm{MCl} \text {. }\end{array}$ \\
\hline Li et al. (17) & $\begin{array}{l}N=865 \\
\text { Aged } 55+\end{array}$ & Xi'an & $\begin{array}{l}\text { Cross-sectional } \\
(2014 / 2015)\end{array}$ & $\begin{array}{l}\mathrm{MMSE}<17 \text { (illiterate) } \\
\leq 20 \text { (primary school education) } \\
\leq 24 \text { (junior school and above) }\end{array}$ & $\begin{array}{l}\text { Significant interaction between abdominal obesity and } \\
\text { diabetes associating with an increased risk of cognitive } \\
\text { impairment. }\end{array}$ \\
\hline Wu et al. (18) & $\begin{array}{l}N=2,065 \\
\text { Aged } 60+\end{array}$ & Wanshoulu District, Beijing & $\begin{array}{l}\text { Cross-sectional } \\
(2009 / 2010)\end{array}$ & $\begin{array}{l}\text { MMSE }<17 \text { (illiterate) } \\
\leq 20 \text { ( } 1-6 \text { years of education) } \\
\leq 24 \text { ( } \geq 7 \text { years of education) }\end{array}$ & $\begin{array}{l}\text { Prevalence of } \mathrm{MCl} \text { was higher in hypertensive than normal } \\
\text { individuals. Among hypertensive patients, the prevalence of } \\
\mathrm{MCl} \text { was lower in those treated than in those not treated. }\end{array}$ \\
\hline Ren et al. (19) & $\begin{array}{l}N=1,171 \\
\text { Aged } 60+\end{array}$ & Tianjin, Northern China & $\begin{array}{l}\text { Cross-sectional } \\
(2014 / 2015)\end{array}$ & $\begin{array}{l}\text { MMSE }<17 \text { (illiterate) } \\
<22 \text { (primary school) } \\
<26 \text { (junior school and above) }\end{array}$ & $\begin{array}{l}\text { In the multivariate analysis, high blood pressure/ stage III } \\
\text { hypertension was associated with cognitive impairment. }\end{array}$ \\
\hline He et al. (20) & $\begin{array}{l}N=227 \\
\text { Aged } 65+\end{array}$ & Tianjin, China & $\begin{array}{l}\text { Cross-sectional } \\
(2014)\end{array}$ & $\begin{array}{l}\text { MMSE scores 18-23: mild Cl } \\
\text { MMSE scores 10-17: moderate Cl } \\
\text { MMSE scores 0-9: severe } \mathrm{Cl}\end{array}$ & $\begin{array}{l}\text { Total cholesterol (TC) was significantly higher in participants } \\
\text { with } \mathrm{MCl} \text {. Elevated } \mathrm{HDL} \text { (high-density lipoprotein cholesterol) } \\
\text { and triglyceride were associated with the occurrence of } \mathrm{MCl} \text {. }\end{array}$ \\
\hline Ma et al. (21) & $\begin{array}{l}N=1,159 \\
\text { Aged } 60+\end{array}$ & $\begin{array}{l}\text { Nationwide, Chinese } \\
\text { Longitudinal Healthy } \\
\text { Longevity Survey }\end{array}$ & $\begin{array}{l}\text { Longitudinal } \\
\text { (2009-2014) }\end{array}$ & Annual cognitive change of MMSE scores & $\begin{array}{l}\text { High TC and low-density lipoprotein cholesterol (LDL-C) in } \\
\text { late-life were associated with greater cognitive decline. }\end{array}$ \\
\hline Zou et al. (22) & $\begin{array}{l}N=597 \\
\text { Aged } 60+\end{array}$ & $\begin{array}{l}\text { Chongqing, Southwest } \\
\text { China }\end{array}$ & $\begin{array}{l}\text { Cross-sectional } \\
(2011 / 2012)\end{array}$ & $\begin{array}{l}\text { Complaint of memory decline for at least } 6 \\
\text { months; objective memory decline via } \\
\text { neuropsychological evaluation, Clinical } \\
\text { Dementia Rating (CDR) score of } 0.5 \text {. }\end{array}$ & $\begin{array}{l}\text { Hypertension, coronary heart disease, TC, and low-density } \\
\text { lipoprotein cholesterol (LDL-C) are independent risk factors } \\
\text { for MC. }\end{array}$ \\
\hline Yin et al. (23) & $\begin{array}{l}N=16,629 \\
\text { Age } 60+\end{array}$ & $\begin{array}{l}\text { Nationwide, Disease } \\
\text { Surveillance Point System }\end{array}$ & $\begin{array}{l}\text { Cross-sectional } \\
(2011 / 2012)\end{array}$ & $\begin{array}{l}\text { MMSE }<17 \text { (illiterate) } \\
\leq 20 \text { (primary school) } \\
\leq 24 \text { (middle school and above) }\end{array}$ & $\begin{array}{l}\text { Chronic respiratory symptoms and self-reported COPD were } \\
\text { strongly associated with cognitive impairment in urban areas. }\end{array}$ \\
\hline Zhou et al. (24) & $\begin{array}{l}N=3,012 \\
\text { Age } 60+\end{array}$ & $\begin{array}{l}\text { Chongqing, Southwest } \\
\text { China }\end{array}$ & $\begin{array}{l}\text { Cross-sectional } \\
(2001)\end{array}$ & $\begin{array}{l}\text { MMSE }<17 \text { (illiterate) } \\
<20 \text { (primary school) } \\
\leq 24 \text { (middle school and above) }\end{array}$ & $\begin{array}{l}\text { Current smoking and daily alcohol consumption were } \\
\text { significantly associated with an increased risk of cognitive } \\
\text { impairment. }\end{array}$ \\
\hline Pan et al. (25) & $\begin{array}{l}N=2,037 \\
\text { Age } 45+\text { women only }\end{array}$ & $\begin{array}{l}\text { China Health and } \\
\text { Retirement Longitudinal } \\
\text { Study }\end{array}$ & $\begin{array}{l}\text { Longitudinal } \\
\text { (2011-2013) }\end{array}$ & $\begin{array}{l}\text { Telephone Interview version of the MMSE - 1) } \\
\text { memory tests and 2) orientation, } \\
\text { visuoconstruction, and numeric ability. }\end{array}$ & $\begin{array}{l}\text { Longer exposure to second hand smoke exposure was } \\
\text { associated with a greater decline in memory over } 2 \text { years, } \\
\text { especially among women aged } 55-64 \text { years }\end{array}$ \\
\hline Zhu et al. (26) & $\begin{array}{l}N=6,586 \\
\text { Age } 65+\end{array}$ & $\begin{array}{l}\text { Chinese Longitudinal } \\
\text { Healthy Longevity Survey }\end{array}$ & $\begin{array}{l}\text { Longitudinal } \\
\text { (2005 and 2008-2009) }\end{array}$ & $\begin{array}{l}\text { MMSE }<18 \text { (no formal education) } \\
<21 \text { ( } 1-6 \text { years of education) } \\
<25 \text { ( }>6 \text { years of education) }\end{array}$ & $\begin{array}{l}\text { High level of participation in leisure activities was associated } \\
\text { with about } 40 \% \text { decreased risk of cognitive impairment. }\end{array}$ \\
\hline
\end{tabular}


lipoprotein cholesterol and triglyceride were associated with the occurrence of MCI (20-22).

\section{Chronic Obstructive Pulmonary Disease}

There is evidence documenting the relationships between chronic obstructive pulmonary disease and cognitive impairment among older Chinese. A nationally representative Chronic Disease and Risk Factor Surveillance study covering 31 provinces across China reported chronic cough, chronic phlegm, and self-reported symptoms in urban areas, but only chronic phlegm in rural areas was associated with cognitive impairment (23). In addition, indoor air pollution, such as exposure to biomass combustions from cooking fuel, could modify the effects of chronic obstructive pulmonary disease on cognitive impairment (23).

\section{Relationships Between Modifiable Health-Risk Factors and Cognitive Impairment \\ Smoking and Alcohol Consumption}

Smoking and alcohol consumption have been found to be major behavioral risk factors for cognitive impairment among older Chinese $(24,25)$. For example, cross-sectional evidence from (aged 60+ in Chongqing) reported that current smoking and daily consumption of alcohol were associated with a significantly increased risk of cognitive impairment (24). Despite of low female smoking in China, further longitudinal evidence from the national China Health and Retirement Longitudinal Study among Chinese nationwide reported that longer exposure to second hand smoke was associated with higher risk of cognitive decline over 2 years, especially among women aged 55-64 years (25).

\section{Exercise and Incidental Physical Activity}

The benefits of being physically active has been widely documented among older Chinese with direct effects across multiple domains of cognitive functions from engaging in modern aerobic and traditional Chinese exercise such as Tai Chi and Qigong (35-37). A systematic review among older Chinese has linked the health benefits of exercise in a range of chronic diseases through lowering elevated blood pressure (hypertension) as well as improving cardiopulmonary and lung functions (38). In addition to exercise, incidental physical or leisure activities such as housework were shown to associate with a $41 \%$ decreased risk and thus protective against cognitive impairment based on the 5-year follow-up of the nationwide Chinese Longitudinal Health Longevity Survey (26).

\section{Common Social Determinants of NCDs and Cognitive Impairment \\ Socio-Economic Status}

Low socioeconomic status has been commonly linked to disparity in mild cognitive impairment $(11,19,39)$. According to the World Health Organization Study on global AGEing and adult health among older Chinese nationally aged 50 years and over, years of education were shown to be significantly associated with cognition scores at the individual level and median household income and median years of education at the community level (40). Using the same data, another study has confirmed that both education level and wealth were negatively associated with untreated chronic non-communicable diseases among older Chinese (41).

\section{Demographic Status}

The role of demographic characteristics, particularly old age and being female is associated with cognitive impairment among older persons across China $(11,19)$. The gender difference may also be a result of women having less access to education $(11,42)$. Solitary status, including never married, divorced, and widowed, is also associated with cognitive impairment among older Chinese (43).

\section{Geographical Areas}

Multiple epidemiological studies have determined that geographical disparities result in an increase in cognitive impairment among older Chinese in rural areas $(39,44)$. Residential status has been linked to a faster decline in cognitive function, not only among rural but also rural-to-urban migrants compared to urban residents as reported by a 12-year follow-up of the Chinese Longitudinal Health Longevity Survey (45). Another study using a 9-year follow-up of the same data revealed rural disadvantage also affected not only cognitive health but also other physical health measures (46).

\section{Strengths and Limitations}

This mini review brings together recent evidence on cognitive and mild cognitive impairment among older Chinese highlighting the link to shared behavioral lifestyle risk factors of cardio-metabolic conditions. The strength of this mini review draws upon many large epidemiological studies across China including longitudinal studies where possible. Notably, the mini review focuses on observational population-based data with less evidence from clinical studies. Because of the smaller scope of the mini review, which is primarily based on international databases, relevant articles in Chinese may be omitted. This could potentially result in under reporting bias in some geographical areas that have limited exposure to English publications.

The definition and severity of cognitive impairment vary across studies, however, most of these studies use international standardized measures. It has been argued that these measures should have differing cut-offs for older and less educated respondents within the Chinese context (47). Care should be taken in the investigation of aging and cultural influence on cognition $(48,49)$. In addition to the importance of culturally appropriate tests in interpreting cognitive impairment, other factors such as cultural specific factors such as regional norms among older Chinese could be further explored. Longitudinal studies could provide insight into mechanisms by which cognitive impairment and NCDs interact. Standardized measures would also allow for possible international comparative studies beyond China in future research. 


\section{Policy Implications}

Under the national Healthy China Initiative, the Chinese government has put in place the plan toward 2025 for the prevention and treatment of chronic non-communicable diseases (50). The first two goals of "... diagnosing diseases in the early stage" and "... advocate a healthy lifestyle" are applicable to both $\mathrm{NCD}$ and $\mathrm{CI} / \mathrm{MCI}$ which share common risk factors. Addressing behavioral risk factors and early detection of NCDs could delay its progression and further complications.

Since the health system reforms in 2009, achieving essential public health services and community-based non-communicable disease management has been rolled out nationwide to improve availability and accessibility of health services (51). Primary health care and community health centers, especially in the rural areas, play a significant role in regular screening for blood pressure or blood glucose in middle-aged and older adults and follow-up management of these conditions $(52,53)$. In line with advocating a healthy lifestyle through self-care education, behavioral, and psychological approaches embedded within primary health care settings could also provide effective intervention in managing chronic conditions such as diabetes (54). Integration of services at both primary and secondary levels is also vital for chronic care management $(5,55)$.

In order to implement these reforms in primary health care settings the health care workforce needs to be upskilled $(50,56)$. The need for more and better trained general practitioners is central to many recent policy statements in China (57). Sun et al. (58) in this Frontiers Special Topic Chronic Illness and Aging in China present a strong argument for the training of general practitioners in China in behavior change and chronic illness management in order to prevent and manage behavioral risk factors in chronic illness. Wang et al. (57) in an analysis of community nurse training courses asked nurses to rank the importance and the utility of various topics. Pertinent to the current paper the authors found that while learning about health behaviors was ranked by nurses as 11 out of 20 topics in terms of importance, content utility was ranked at 15 . In the subsequent modified curriculum, methods and skills involved in health education and promotion, impacts of unhealthy behaviors and interventions for unhealthy behaviors were included as well as management of chronic disease in the community.

The recent World Bank China Joint Study Partnership Health Policy Summary "Deepening health reform in China" (56) advocates a People-Centered Integrated Care Model to address the burden of chronic illness in China. It proposes an expanded and empowered role for citizens in the management of their health through building health literacy, strengthening patient self-management, and improving shared decision making. This

\section{REFERENCES}

1. IHME. Global Burden of Disease. Institute for Health Metrics and Evaluation Seattle, Washington (2016).

2. Wu YT, Ali GC, Guerchet M, Prina AM, Chan KY, Prince M, et al. Prevalence of dementia in mainland China, Hong Kong and Taiwan: an updated model has the potential to address risk factors and the management of chronic illnesses in China but will require an investment in the training of doctors in the areas of selfmanagement and behavior change and the education of citizens in the prevention of chronic illness.

As well as training the healthcare workforce in peoplecentered care, risk factor and chronic disease management; and the empowerment of patients in the management of their illness, system level changes are also needed. In addition to workforce strengthening and engaging citizens in their health care, the Deepening Health Reform in China policy statement identifies another six levers of reform including shaping a tiered health care delivery system, improving quality of care, reforming public hospitals, realigning purchaser and provider payment incentives; strengthening the health care private sector and modernizing health service planning [(56) p. xviii].

Given our current knowledge about the relationships between NCDs and cognitive impairment it is important that early public health interventions and primary health care services address risk factors across the lifecourse and that these interventions and services are well-targeted. We argue that attention to prevention through reducing behavioral risk factors such as excess tobacco and alcohol consumption and physical inactivity and the management of abnormal blood pressure and blood glucose all have the potential to impact positively on cognitive and mild cognitive impairment and non-communicable diseases in China.

\section{AUTHOR CONTRIBUTIONS}

VY and CB conceptualized the study, drafted the manuscript, and finalized revisions for publication.

\section{FUNDING}

This study received support from the Australian Research Council (ARC), Discovery Project Understanding aging in China and Australia (DP16010323), the ARC Centre of Excellence in Population Ageing Research (CEPAR grant numbers CE1101029 and CE1701005), and The Sanming Project of Medicine in Shenzhen, Sanming Project team code: SZSM201511046.

\section{ACKNOWLEDGMENTS}

The authors thank the late Emeritus Professor Hal Kendig who passed away before the manuscript submission. Prof. Kendig contributed significantly to the conceptualization of this study. Overall editorial guidance was provided by Peter Sbirakos throughout the process. systematic review and meta-analysis. Int I Epidemiol. (2018) 47:709-19. doi: 10.1093/ije/dyy007

3. WHO. Package of Essential Noncommunicable (PEN) Disease Interventions for Primary Health Care in LowResource Settings. World Health Organization, Geneva (2010). 
4. Yiengprugsawan V, Healy J, Kendig H. Health System Responses to Population Ageing and Noncommunicable Diseases in Asia. Comparative Country Studies. New Delhi: World Health Organization (2016).

5. WHO. China Country Assessment Report on Ageing and Health. World Health Organization, Geneva (2015).

6. Baumgart M, Snyder HM, Carrillo MC, Fazio S, Kim H, Johns H. Summary of the evidence on modifiable risk factors for cognitive decline and dementia: a population-based perspective. Alzheimers Dement. (2015) 11:71826. doi: $10.1016 /$ j.jalz.2015.05.016

7. Menzies V, Kelly DL, Yang GS, Starkweather A, Lyon DE. A systematic review of the association between fatigue and cognition in chronic noncommunicable diseases. Chronic Illn. (2019). doi: 10.1177/1742395319836472. [Epub ahead of print].

8. Stein DJ, Benjet C, Gureje O, Lund C, Scott KM, Poznyak V, et al. Integrating mental health with other non-communicable diseases. BMJ. (2019) 364:1295. doi: $10.1136 / \mathrm{bmj} .1295$

9. United Nations. 2030 Sustainable Development Goals. (2018). Available online at: https://sustainabledevelopment.un.org/sdgs (accessed November 02, 2018).

10. Li Y, Zeng X, Liu J, Liu Y, Liu S, Yin P, et al. Can China achieve a one-third reduction in premature mortality from non-communicable diseases by 2030 ? BMC Med. (2017) 15:132. doi: 10.1186/s12916-017-0894-5

11. Nie H, Xu Y, Liu B, Zhang Y, Lei T, Hui X, et al. The prevalence of mild cognitive impairment about elderly population in China: a meta-analysis. Int J Geriatr Psychiatry. (2011) 26:558-63. doi: 10.1002/gps.2579

12. Xue J, Li J, Liang J, Xie L, Chen S. The prevalence of mild cognitive impairment in China: a systematic review. Aging Dis. (2018) 9:706-15. doi: 10.14336/AD.2017.0928

13. US. CDC. Cognitive Impairment: A Call for Action, Now! Centers for Disease Control and Prevention (2011). Available online at: https://www.cdc.gov/ aging/pdf/cognitive_impairment/cogimp_poilicy_final.pdf

14. Gao Y, Xiao Y, Miao R, Zhao J, Cui M, Huang G, et al. The prevalence of mild cognitive impairment with type 2 diabetes mellitus among elderly people in China: a cross-sectional study. Arch Gerontol Geriatr. (2016) 62:138-42. doi: $10.1016 /$ j.archger.2015.09.003

15. Li W, Wang T, Xiao S. Type 2 diabetes mellitus might be a risk factor for mild cognitive impairment progressing to Alzheimer's disease. Neuropsychiatr Dis Treat. (2016) 12:2489-95. doi: 10.2147/NDT.S111298

16. Wang F, Zhao M, Han Z, Li D, Zhang S, Zhang Y, et al. Association of body mass index with amnestic and non-amnestic mild cognitive impairment risk in elderly. BMC Psychiatry. (2017) 17:334. doi: 10.1186/s12888-017-1493-x

17. Li Y, Shang S, Fei Y, Chen C, Jiang Y, Dang L, et al. Interactive relations of type 2 diabetes and abdominal obesity to cognitive impairment: a crosssectional study in rural area of Xi'an in China. J Diabetes Complications. (2018) 32:48-55. doi: 10.1016/j.jdiacomp.2017.09.006

18. Wu L, He Y, Jiang B, Liu M, Wang J, Yang S, et al. The association between the prevalence, treatment and control of hypertension and the risk of mild cognitive impairment in an elderly urban population in China. Hypertens Res. (2016) 39:367-75. doi: 10.1038/hr.2015.146

19. Ren L, Bai L, Wu Y, Ni J, Shi M, Lu H, et al. Prevalence of and risk factors for cognitive impairment among elderly without cardio- and cerebrovascular diseases: a population-based study in rural China. Front Aging Neurosci. (2018) 10:62. doi: 10.3389/fnagi.2018.00062

20. He Q, Li Q, Zhao J, Wu T, Ji L, Huang G, et al. Relationship between plasma lipids and mild cognitive impairment in the elderly Chinese: a case-control study. Lipids Health Dis. (2016) 15:146. doi: 10.1186/s12944-016-0320-6

21. Ma C, Yin Z, Zhu P, Luo J, Shi X, Gao X. Blood cholesterol in latelife and cognitive decline: a longitudinal study of the Chinese elderly. $\mathrm{Mol}$ Neurodegener. (2017) 12:24. doi: 10.1186/s13024-017-0167-y

22. Zou Y, Zhu Q, Deng Y, Duan J, Pan L, Tu Q, et al. Vascular risk factors and mild cognitive impairment in the elderly population in Southwest China. Am J Alzheimers Dis Other Dement. (2014) 29:242-7. doi: $10.1177 / 1533317513517042$

23. Yin $\mathrm{P}, \mathrm{Ma} \mathrm{Q}$, Wang L, Lin $\mathrm{P}$, Zhang $\mathrm{M}$, Qi S, et al. Chronic obstructive pulmonary disease and cognitive impairment in the Chinese elderly population: a large national survey. Int J Chron Obstruct Pulmon Dis. (2016) 11:399-406. doi: 10.2147/COPD.S96237
24. Zhou H, Deng J, Li J, Wang Y, Zhang M, He H. Study of the relationship between cigarette smoking, alcohol drinking and cognitive impairment among elderly people in China. Age Ageing. (2003) 32:205-10. doi: 10.1093/ageing/32.2.205

25. Pan X, Luo Y, Roberts A. Secondhand smoke and women's cognitive function in China. Am J Epidemiol. (2018) 187:911-8. doi: 10.1093/aje/kwx377

26. Zhu X, Qiu C, Zeng Y, Li J. Leisure activities, education, and cognitive impairment in Chinese older adults: a population-based longitudinal study. Int Psychogeriatr. (2017) 29:727-39. doi: 10.1017/S1041610216001769

27. Petersen RC, Smith GE, Waring SC, Ivnik RJ, Tangalos EG, Kokmen E. Mild cognitive impairment: clinical characterization and outcome. Arch Neurol. (1999) 56:303-8. doi: 10.1001/archneur.56.3.303

28. Portet F, Ousset PJ, Visser PJ, Frisoni GB, Nobili F, Scheltens P, et al. Mild cognitive impairment (MCI) in medical practice: a critical review of the concept and new diagnostic procedure. Report of the MCI Working Group of the European Consortium on Alzheimer's Disease. J Neurol Neurosurg Psychiatry. (2006) 77:714-8. doi: 10.1136/jnnp.2005.085332

29. Reisberg B, Ferris SH, Kluger A, Franssen E, Wegiel J, de Leon MJ. Mild cognitive impairment (MCI): a historical perspective. Int Psychogeriatr. (2008) 20:18-31. doi: $10.1017 /$ S1041610207006394

30. Cheng Y, Xiao S. Recent research about mild cognitive impairment in China. Shanghai Arch Psychiatry. (2014) 26:4-14. doi: 10.3969/j.issn.1002-0829.2014.01.002

31. Giri M, Chen T, Yu W, Lu Y. Prevalence and correlates of cognitive impairment and depression among elderly people in the world's fastest growing city, Chongqing, People’s Republic of China. Clin Interv Aging. (2016) 11:1091-8. doi: 10.2147/CIA.S113668

32. Wang Y, Song M, Yu L, Wang L, An C, Xun S, et al. Mild cognitive impairment: vascular risk factors in community elderly in four cities of Hebei Province, China. PLoS ONE. (2015) 10:e0124566. doi: 10.1371/journal.pone.0124566

33. Chen RH, Jiang XZ, Zhao XH, Qin YL, Gu Z, Gu PL, et al. Risk factors of mild cognitive impairment in middle aged patients with type 2 diabetes: a cross-section study. Ann Endocrinol. (2012) 73:208-12. doi: 10.1016/j.ando.2012.04.009

34. Yong J, Lin D, Tan XR. Primary prevention of cardiovascular disease in older adults in China. World J Clin Cases. (2017) 5:349-59. doi: 10.12998/wjcc.v5.i9.349

35. Lee AT, Richards M, Chan WC, Chiu HF, Lee RS, Lam LC. Intensity and types of physical exercise in relation to dementia risk reduction in community-living older adults. J Am Med Dir Assoc. (2015) 16:899 e891-7. doi: 10.1016/j.jamda.2015.07.012

36. Lü J, Fu W, Liu Y. Physical activity and cognitive function among older adults in China: a systematic review. J Sport Health Sci. (2016) 5:287-96. doi: 10.1016/j.jshs.2016.07.003

37. Xu L, Jiang CQ, Lam TH, Zhang WS, Thomas GN, Cheng KK. Dose-response relation between physical activity and cognitive function: Guangzhou biobank cohort study. Ann Epidemiol. (2011) 21:857-63. doi: 10.1016/j.annepidem.2011.06.002

38. Guo Y, Shi H, Yu D, Qiu P. Health benefits of traditional Chinese sports and physical activity for older adults: a systematic review of evidence. J Sport Health Sci. (2016) 5:270-80. doi: 10.1016/j.jshs.2016.07.002

39. Rao D, Luo X, Tang M, Shen Y, Huang R, Yu J, et al. Prevalence of mild cognitive impairment and its subtypes in community-dwelling residents aged 65 years or older in Guangzhou, China. Arch Gerontol Geriatr. (2017) 75:70-5. doi: 10.1016/j.archger.2017.11.003

40. Wu F, Guo Y, Zheng Y, Ma W, Kowal P, Chatterji S, et al. Social-economic status and cognitive performance among Chinese aged 50 years and older. PLoS ONE. (2016) 11:e0166986. doi: 10.1371/journal.pone.0166986

41. Arokiasamy P, Uttamacharya KP, Capistrant BD, Gildner TE, Thiele E, Biritwum RB, et al. Chronic noncommunicable diseases in 6 low- and middleincome bountries: findings from wave 1 of the World Health Organization's Study on Global Ageing and Adult Health (SAGE). Am J Epidemiol. (2017) 185:414-28. doi: 10.1093/aje/kww125

42. Lei X, Smith JP, Sun X, Zhao Y. Gender differences in cognition in China and reasons for change over time: evidence from CHARLS. J Econ Ageing. (2014) 4:46-55. doi: 10.1016/j.jeoa.2013.11.001 
43. Feng L, Ng XT, Yap P, Li J, Lee TS, Hakansson K, et al. Marital status and cognitive impairment among community-dwelling Chinese older adults: the role of gender and social engagement. Dement Geriatr Cogn Dis Extra. (2014) 4:375-84. doi: 10.1159/000358584

44. Jia J, Zhou A, Wei C, Jia X, Wang F, Li F, et al. The prevalence of mild cognitive impairment and its etiological subtypes in elderly Chinese. Alzheimers Dement. (2014) 10:439-47. doi: 10.1016/j.jalz.2013.09.008

45. Xu H, Dupre ME, Gu D, Wu B. The impact of residential status on cognitive decline among older adults in China: results from a longitudinal study. BMC Geriatr. (2017) 17:107. doi: 10.1186/s12877-017-0501-9

46. Zhang X, Dupre ME, Qiu L, Zhou W, Zhao Y, Gu D. Urban-rural differences in the association between access to healthcare and health outcomes among older adults in China. BMC Geriatr. (2017) 17:151. doi: 10.1186/s12877-0170538-9

47. Mellor D, Lewis M, McCabe M, Byrne L, Wang T, Wang J, et al. Determining appropriate screening tools and cut-points for cognitive impairment in an elderly Chinese sample. Psychol Assess. (2016) 28:1345-53. doi: $10.1037 /$ pas0000271

48. Fung HH. Aging in culture. Gerontologist. (2013) 53:369-77. doi: 10.1093/geront/gnt024

49. Park DC, Nisbett R, Hedden T. Aging, culture, and cognition. J Gerontol B Psychol Sci Soc Sci. (1999) 54:P75-84. doi: 10.1093/geronb/54B.2.P75

50. The State Council People's Republic of China. State Council Issues Plan to Prevent Chronic Diseases. (2017). Available online at: http://english.gov.cn/ policies/latest_releases/2017/02/14/content_281475567482818.htm (accessed November 02, 2018).

51. Communist Party of China Central Committee People's Republic of China. Implementation Plan for the Recent Priorities of the Health Care System Reform (2009-2011). (2009). Available online at: http://www.china.org.cn/ government/scio-press-conferences/2009-04/09/content_17575401.htm (accessed November 02, 2018).

52. Feng YJ, Wang HC, Li YC, Zhao WH. Hypertension screening and follow-up management by primary health care system among Chinese population aged 35 years and above. Biomed Environ Sci. (2015) 28:330-40. doi: $10.3967 /$ bes 2015.047
53. Tian $\mathrm{M}$, Wang $\mathrm{H}$, Tong $\mathrm{X}$, Zhu K, Zhang $\mathrm{X}$, Chen X. Essential public health services' accessibility and its determinants among adults with chronic diseases in China. PLoS ONE. (2015) 10:e0125262. doi: 10.1371/journal.pone. 0125262

54. Browning CJ, Yang $\mathrm{H}$, Zhang $\mathrm{T}$, Chapman A, Liu S, Enticott J, et al. Implementing a chronic disease self-management program into China: the Happy Life Club. Front Public Health. (2014) 2:181. doi: 10.3389/fpubh.2014.00181

55. Xiao Y. Community-based integration of management of noncommunicable diseases in China. Chronic Dis Transl Med. (2015) 1:133-40. doi: 10.1016/j.cdtm.2015.07.001

56. World Bank China Joint Study Partnership. Deepening Health Reform in China: Building High-Quality and Value-Based Service Delivery. Washington, DC: World Bank Group, World Health Organization, Ministry of Finance, National Health and Family Planning Commission, Ministry of Human Resources and Social Security (2016)

57. Wang S, Chen W, Du Y. Improving the curriculum for a community nursing training program in Guangzhou City, China. Public Health Nurs. (2019) 36:70-8. doi: 10.1111/phn.12562

58. Sun W, Li Y, Hu Y, Rao X, Xu X, Browning CJ, et al. Perspectives on the training of Chinese primary health care physicians to reduce chronic illnesses and their burden. Front Public Health. (2019) 7:168. doi: $10.3389 /$ fpubh.2019.00168

Conflict of Interest: The authors declare that the research was conducted in the absence of any commercial or financial relationships that could be construed as a potential conflict of interest.

Copyright (C) 2019 Yiengprugsawan and Browning. This is an open-access article distributed under the terms of the Creative Commons Attribution License (CC BY). The use, distribution or reproduction in other forums is permitted, provided the original author(s) and the copyright owner(s) are credited and that the original publication in this journal is cited, in accordance with accepted academic practice. No use, distribution or reproduction is permitted which does not comply with these terms. 